\title{
Program-Length Commercials and Host Selling by the WWF
}

\author{
KEVIN J. SHANAHAN AND MICHAEL R. HYMAN
}

$\mathrm{W}$

hether for automobiles, universities, golf courses, or ski slopes, the basic raison d'être for ratings systems is identical: to enable consumers to make more informed choices by attaching meaningful labels to competing offerings. For example, to help potential viewers make more informed decisions about which movies to watch, the Motion Picture Association of America adopted a voluntary ratings system that signals violent, sexual, or adult-oriented content. To help voters make informed decisions on election-day, a political action group may rate candidates based on their stated positions and voting records.

Unfortunately, negative and unintended consequences may attend the use of any ratings system, such as the one now used in the United States to rate television programs. This age-based ratings system creates a forbidden fruit effect, ${ }^{1}$ which according to the theory of psychological reactance occurs when freedoms are restricted (i.e., people are motivated to assert their independence by performing forbidden acts). ${ }^{2}$ For example, violent television programming becomes more attractive to children when viewership is restricted, by advisories or ratings. ${ }^{3}$ Such behavior did not go unnoticed by the entertainment industry. The recent U.S. Federal Trade Commission report on violence in the media confirmed that Hollywood has targeted underaged youths for violent movies, music, and video games, even when such materials are labeled as adult-only fare. ${ }^{4}$

Kevin J. Shanahan is Assistant Professor of Marketing in the College of Business at The University of Texas at Tyler. Michael R. Hyman is Professor of Marketing, College of Business Administration and Economics, New Mexico State University. 
To satisfy child advocacy groups, to address flaws in the thencurrent A. C. Neilsen system, and to cope with the aforementioned forbidden fruits effect, a new ratings system designed to work with a V (for violence) chip-a dedicated semi-conductor processor that would be installed in all televisions with 13 or more inch screenswas introduced in 1996. The V-chip reads information "about violence, sexual situations, language content and adult dialogue, encoded in the rated program and blocks programs from the set based upon the rating selected by the parent."

In the absence of v-chip technology, i.e., if compliance by children were voluntary, the forbidden fruit problem would likely prove significant without vigilant parental supervision. With v-chip technology, the issue is whether or not the ratings system properly identifies all broadcast content. Armed with this new hardwaresoftware solution, parents can program their televisions to automatically screen shows based on the recommended minimum viewer age, the ratings system (i.e., "S" for sexual situations, "L" for language, "V" for violence, and " $\mathrm{D}$ " for adult dialogue), or a combination of the two. ${ }^{6}$

The use of host selling and program-length commercials targeted at children was banned by the U.S. Federal Trade Commission (FTC) in 1974 and the U.S. Children's Television Act of 1990. The issue, therefore, is whether or not the current ratings system and v-chip screen children from these banned advertising techniques. Unfortunately, this technology was not designed to help parents block either technique. In other words, because federal regulations ban U.S. advertisers from using either technique when advertising to children, such commercials are unanticipated and thus not blocked by the current screening technology.

Uncoordinated government regulation is not a new phenomenon. A study of violence in commercials targeted at children shows that the FCC and FTC, which hold dual jurisdiction over the programming content and commercials aimed at children, failed to coordinate their efforts in this case. ${ }^{7}$ Specifically, Saturday morning cartoon programs were found to contain advertisementswhich, unlike programs, are unfiltered by the v-chip-with excessive violence. Thus, the problem we identify is consistent with a general pattern of uncoordinated regulation among government agencies. 


\section{HOST SELLING}

Host selling is "the use of program talent to deliver commercials," including "endorsements or selling by animated cartoon characters as well as 'live' program hosts." ${ }^{8}$ Born on radio and popularized on television, host selling is (a) direct selling by the host or other performer while in character (e.g., Howdy Doody endorsing Ovaltine), ${ }^{9}$ (b) ads and storylines so tightly meshed as to be indistinguishable (e.g., "advertisements featuring the same type of animation that is regularly featured in the accompanying program"), ${ }^{10}$ or (c) suggestive selling by within-program characters (e.g., Bananas in Pajamas characters appearing in commercials for Bananas in Pajamas videos during a Bananas in Pajamas program). ${ }^{11}$ During the 1950 s host selling characterized roughly half of all television commercials; furthermore, 31.7 percent of such commercials were integral to or indistinguishable from preceding and subsequent program segments. Given the increased credibility of host sellers, the advertising agencies that then controlled productions benefited from this blurring of content. ${ }^{12}$

A variation of host selling was the segue commercial, which was delineated from the program by a change of set or a fading to black and then returning, but the costumes and set still resembled those of the program. ${ }^{13}$ For example, regular cast members on the Mickey Mouse Club might promote a toy while standing on a Disneyesque set, or Sheri Lewis (puppet Lambchop's ventriloquist) might cease her in-program activities, turn to the camera, and say something like "It's time to talk about Skippy peanut butter."

Program-length commercials targeted at children are also problematic. The FCC has argued that program-length commercials are

extremely serious violations of the children's television commercial limits, [and] that the program-length commercial policy directly addresses a fundamental regulatory concern, that children who have difficulty enough distinguishing program content from unrelated commercial matter, not be all the more confused by a show that interweaves program content and commercial matter. ${ }^{14}$

Three examples of programming in which children were thought to be unable to differentiate between characters and host sellers, and thus ruled a program-length commercial, include: 
1. Teenage Mutant Ninja Turtle. The characters in this cartoon program appeared in commercials for action figures based on these characters.

2. The Flintstones. Fred Flintstone, the main cartoon character of this program, appeared in commercials for Fruity Pebbles breakfast cereal. The cereal is named after Fred Flintstone's daughter, Pebbles.

3. Bananas in Pajamas. During the airing of the Bananas in Pajamas program, an advertisement appeared for Bananas in Pajamas on videotape. ${ }^{15}$

Despite clear prohibitions on host selling (since 1974) and program-length commercials (since 1992) targeted at children, the Federal Communication Commission (FCC) enforcement page (http://www.fcc.gov/cgi-bin/AT-fcc_websearch.cgi) lists 37 post1998 violations. ${ }^{16}$ Television stations airing children's programs, such as Bananas in Pajamas, Goof Troop, Sonic the Hedgehog, and Teenage Mutant Ninja Turtles, have been legally cited as primary offenders. Penalties have included fines of $\$ 10,000$ and threat of refusal to re-license the station. Thus, continuing violations of the Children's Television Act of 1990 have included both host selling and program-length commercials.

\section{New Formal Definition of Host Selling}

Unlike standard product endorsements, host selling, as now formally defined here, satisfies two conditions:

1. The host of a program promotes a product directly, either during (a) the program, or (b) a faux continuation of the program expressly designed to resemble the program; and

2. The promoted product is purchased or consumed through a different channel than the program is viewed.

For example, Bananas in Pajamas characters promoting a Bananas in Pajamas videotape during a Bananas in Pajamas program is host selling because the characters promote the videotape directly and it must be purchased separately. In contrast, booth announcers publicizing an upcoming $\mathrm{ABC}$ network broadcast during a Monday Night Football game is not host selling because both broadcasts are purchased and consumed identically (i.e., both are free broadcasts by a major television network; no additional 
purchase is necessary). In addition, product placement-in which a product is shown incidentally in return for a fee-is not host selling because the practice is meant only to increase brand awareness and the actors remain "in character" when handling the product. ${ }^{17}$

Given this framework, the World Wrestling Federation (WWF), through its weekly televised evening broadcasts, is a major violator of the strictures on host selling and program-length commercials. A review of their programs demonstrates repeated host selling for pay-per-view events. Unfortunately, the current U.S. television ratings system fails to alert the v-chip to block older children, who constitute a major audience segment for televised wrestling, from viewing these WWF broadcasts. This example is now discussed in detail.

\section{WWF PROGRAMMING}

With more than 5 million viewers, RAW IS WAR, the WWF's weekly flagship program on the USA network (but recently moved to TNN), is the highest-rated program on U.S. cable television; Smackdown, the WWF's weekly program on the UPN network, draws almost 5 million viewers. ${ }^{18}$ On average, the 35 million U.S. fans of the WWF and rival WCW (World Championship Wrestling) watch 15 hours per week of wrestling programs. ${ }^{19}$ Although WWF broadcasts attract an audience that is 70 percent male, ${ }^{20}$ viewers belong to many demographic segments (e.g., women are the fastest-growing segment). The three largest audience groups are 6 to 17 year olds (especially 11 to 15 year olds), 18 to 44 year old men, and 18 to 24 year old women. ${ }^{21}$ Pre-teens constitute more than 15 percent of the audience. ${ }^{22}$ To accommodate these younger viewers, the WWF tempers the violence and sexual innuendo on its weekend morning programs.

The WWF's more than one-half million U.S. fans part with $\$ 30$ million a month for its pay-per-view programs, such as King of the Ring. ${ }^{23}$ During the month preceding a King of the Ring pay-per-view tournament, the weekly evening broadcasts show matches intended to eliminate the loser from competing in that tournament. The field is ultimately narrowed to the eight wrestlers who will compete for the title King of the Ring. The tournament is repeatedly promoted as a springboard for lesser-known wrestlers to join professional wrestling's elite. 
All pay-per-view tournaments are scheduled immediately after the Sunday evening program HEAT, which is used to promote the event; tournament results are announced the next night on RAW IS WAR. Unlike many pay-cable programs, these tournaments are never re-broadcast on U.S. stations such as USA, TNT, or WTBS. Still photographs are used to promote a pay-per-view re-broadcast of the event the following night (Tuesday; a non-wrestling night for the WWF). The winner of King of the Ring is touted as the newest icon in professional wrestling's upper echelon. Of course, "winner" is somewhat of a misnomer; in 1989, Vince McMahon admitted, while under investigation by the New Jersey Gaming Commission, that the matches are scripted. ${ }^{24}$

\section{Representative WWF Storylines}

A typical two-hour RAW IS WAR contains only 36 minutes of wrestling; the remaining 84 minutes is dedicated to a soap opera storyline and commercials. ${ }^{25}$ As now formulated, professional wrestling is a "soap opera for guys," with programs depicting betrayal, payback, shifting alliances, and grudge matches. The storylines are often complex and involve the WWF's owners, the wrestlers and their managers, and even non-wrestling celebrities.

Two recent storylines capture the soap operatic nature and cartoonish personae that characterize professional wrestling. One storyline follows the tumultuous relationship between Triple $\mathrm{H}$ (multi-time WWF champion) and Stephanie McMahon-Helmsly (daughter of owner Vince McMahon, wife of Triple H, and current WWF women's champion). The ever-jealous Triple $\mathrm{H}$ continually finds Stephanie in seemingly compromising yet innocent situations, à la the hit 1970s U.S. television sitcom Three's Company. For example, one Sunday on HEAT, Triple H stumbled across an innocent, post-title-defense embrace between Stephanie and Kurt Angle (Olympic Gold Medalist and current King of the Ring). Ire raised, Triple H pummeled Angle repeatedly. Early the next Thursday on Smackdown, Stephanie is shown scolding Triple H over his jealousy and telling him that she and Angle are "just friends." Later that evening, Triple $\mathrm{H}$ caught Stephanie hugging Angle again as she wished him good luck on an upcoming bout. The hug lingered a bit and Triple $\mathrm{H}$ saw her caress Angle's back. To settle his growing grudge with Angle, Triple H asked Commissioner Mick Foley (a.k.a. 
Mankind, Cactus Jack, and Dude Love; a retired, multi-personality WWF champion) to arrange a bout, with the WWF championship at stake. However, before Triple $\mathrm{H}$ and Angle could retire to their respective locker rooms, the Rock (nemesis to both Triple $\mathrm{H}$ and the entire McMahon family) appeared and demanded that he, as the top-ranked contender, should "get the title shot." Triple $\mathrm{H}$ then agreed to wrestle both Angle and the Rock to establish the undisputed WWF champion.

Another storyline dramatized a feud between the male (Vince and son Shane) and female (wife Linda and daughter Stephanie) members of the McMahon family, who jointly own the WWF. The McMahon women-50 percent owners-granted their decisionmaking proxy to Stone Cold Steve Austin, a popular wrestler and Vince's television nemesis. Once named the new CEO of the WWF, Austin played several mean pranks on Vince (e.g., dumping horse manure on Vince's desk, driving a beer truck up to the ring and dousing Vince and Shane with beer). To settle the conflict, a bout between Austin and the two McMahon men was scheduled. The stakes: the McMahon men's 50 percent ownership of the WWF versus Austin's resignation as CEO of the WWF. Of course, viewers could only watch this grudge match on the next pay-per-view broadcast. The scenario is the same for each pay-per-view event; a grudge is established during free programming and is settled on pay-per-view programming.

\section{THE WWF AND HOST SELLING}

As Brad Sielgel, formerly the president of the rival WCW, recently claimed, "my pitch is that when somebody buys advertising, one of the most important things to look for is an environment where the consumer is totally involved in the environment and story. I have those environments." ${ }^{26}$ Because viewers are highly involved with wrestling programming in general, the WWF can work pay-per-view programs into the storyline in the guise of matches to resolve grudges fostered during weekly broadcasts. This effort to interweave advertising and programming is a form of host selling. The WWF interweaving its pay-per-view advertisements and programming into an undifferentiated melange satisfies the first condition of host selling and program-length commercials; the host and 
wrestlers promote a different product directly (i.e., the pay-per-view program). The FCC contends that if "a program [is] associated with a product in which commercials for that product are aired . . . [then] the entire program [is] to be counted as commercial time." 27 Pay-per-view events are analogous to live videotapes. In this context (live videotapes), pay-per-view programming is distributed differently from free broadcast programming and thus satisfies the second condition of host selling and program-length commercials.

In addition to upcoming pay-per-view events, other examples of host selling occur during WWF programming. Some examples include the use of on-air talent, like the wrestling team the Hardy Boyz, to promote sponsor (Chef Boy-R-Dee) products during commercials directly preceding a wrestling match involving the same wrestlers. This is similar to the commercial featuring Fred Flintstone promoting a cereal, Fruity Pebbles, during an airing of The Flintstones. Again, this infraction (Fruity Pebbles) drew a $\$ 10,000$ fine for the television station that aired the commercial during this program.

In another example, a compact disc containing the opening music themes for WWF wrestlers was promoted using host selling. Wrestlers Scotty Too Hotty and Grand Master Sexay were first shown listening to their opening theme on a portable CD player, with the WWF Music Volume $5 \mathrm{CD}$ propped up to show the cover. In the next scene, they enter the ring to the same song while a graphic promoting the CD is superimposed on the television screen. Similarly, the commercial for toy figures of the Teenage Mutant Ninja Turtles, when aired during the program featuring the Teenage Mutant Ninja Turtles, was deemed a program-length commercial by the FCC. ${ }^{28}$

In contrast to the above examples, the WWF does not air similar content (i.e., host selling and program-length commercials) during Saturday morning programming (see Table 1), strongly suggesting the recognition of the FCC ban. Thus, the WWF seemingly attempts to differentiate between the adult-oriented and child-targeted advertising methods.

All regularly scheduled WWF Saturday morning programming -SUPERSTARS—and evening programming-RAW IS WAR and HEAT - which run on the USA network, was videotaped for the four weeks before the King of the Ring pay-per-view specials for June 1999 and June 2000. For coding purposes, either (1) direct selling 
TABLE 1 Host Selling Occurrences on WWF Programs

\begin{tabular}{lrlc}
\hline Year & $\begin{array}{c}1999 \\
\text { Mentions } \\
\text { of King of } \\
\text { the Ring }\end{array}$ & \multicolumn{1}{c}{ Program } & $\begin{array}{c}2000 \\
\text { Mentions } \\
\text { of King of } \\
\text { the Ring }\end{array}$ \\
\hline RAW IS WAR - Week 1 & 16 & RAW IS WAR - Week 1 & 12 \\
RAW IS WAR - Week 2 & 9 & RAW IS WAR - Week 2 & 6 \\
RAW IS WAR - Week 3 & 14 & RAW IS WAR - Week 3 & 11 \\
RAW IS WAR - Week 4 & 18 & RAW IS WAR - Week 4 & 11 \\
HEAT - Week 1 & 49 & HEAT - Week 1 & 51 \\
HEAT - Week 2 & 57 & HEAT - Week 2 & 58 \\
HEAT - Week 3 & 52 & HEAT - Week 3 & 60 \\
HEAT - Week 4 & 76 & HEAT - Week 4 & 82 \\
SUPERSTARS - Week 1 & 0 & SUPERSTARS - Week 1 & 0 \\
SUPERSTARS - Week 2 & 0 & SUPERSTARS - Week 2 & 0 \\
SUPERSTARS - Week 3 & 0 & SUPERSTARS - Week 3 & 0 \\
SUPERSTARS - Week 4 & 0 & SUPERSTARS - Week 4 & 0 \\
& & & \\
\hline
\end{tabular}

Note: Both RAW IS WAR and HEAT are rated TV-14; SUPERSTARS is rated TV-G.

by the McMahons, the ring announcers, and/or the wrestlers, or (2) interwoven programming to promote the upcoming King of the Ring pay-per-view broadcast, was considered host selling. Although a somewhat liberal measure, any utterance of King of the Ring and/or the identification of the King of the Ring as a pay-per-view event by any member of the aforementioned groups or during the interwoven programming counted as a separate act of host selling. This satisfies both conditions of host selling and program-length commercials. Two coders, who independently viewed all 24 hours of videotaped programming, counted 582 utterances of King of the Ring. Even accounting for the liberal measure, host selling is clearly a frequent occurrence on the WWF's evening broadcasts.

\section{CONTINUING PUBLIC POLICY PROBLEM}

Parent groups led the effort to ban host selling. The issue is not whether parents view host selling to children as problematicclearly they do-but rather whether they recognize the advertising methods used by the WWF as host selling and program-length commercials. We ran a pilot study on a convenience sample of 98 
advertising students. These students had just finished covering the topic of host selling and product placement, yet only three of them identified the use of host selling by the WWF during a five-minute video clip in which it occurred three times. One of the three occurrences of host selling involved the announcer telling viewers "to order King of the Ring from their cable company this Sunday for $\$ 29.95$, only on pay-per-view." Furthermore, 75 percent of students were able to identify the pay-per-view event using unaided recall, suggesting the effectiveness of the surreptitious use of host selling by the WWF. Thus, even adults often fail to recognize host selling and program-length commercials, so children are unlikely to identify such banned techniques.

Given the previous efforts of parent groups to ban host selling, it is likely that they would share the concerns of groups like the Parent's Television Council (PTC) were they to become aware of the continued misuse of this advertising technique. The PTC's primary mission is to serve as the conscience of the entertainment industry and corporate advertisers who sponsor television..$^{29}$ As this conscience, monitoring the use of banned advertising techniques certainly falls within their mission. In addition, U.S. government agencies, having banned host selling and program-length commercials aimed at children, have shown that they take immediate corrective measures once they are made aware of infractions, as evidenced by the 37 separate fines levied on television stations.

\section{Conflicting Definitions of a Child}

The FCC defines a child as someone under the age of 17, yet RAW IS WAR, Smackdown, and HEAT are rated TV-14. As the largest viewer segment for professional wrestling is 6 to 17 year olds, this inconsistency is meaningful. Although the TV-14 rating means that parents could block children less than 14 years old from viewing these programs, 14 to 16 year olds, who fall into the largest segment of wrestling fans, would not be excluded. So, contrary to the Children's Television Act of 1990, the WWF is host selling to children.

This public policy problem could be remedied in five ways. First, the WWF could be rated TV-MA for its weekly evening broadcasts. This remedy is unlikely because (1) a TV-MA rating is reserved for the most sexually explicit, graphically violent, or crude-languagefilled programs, which are typically limited to pay cable channels 
such as HBO and Showtime, and (2) weekly evening wrestling broadcasts meet current requirements for a TV-14 rating.

Second, the FCC could ban all host selling. Given that the Children's Television Act of 1990 was drafted to address concerns about advertising to children in general, which includes host selling, it is unlikely that the FCC would take this drastic action. The FCC, by drafting a separate set of regulations for children, implied that adults can either recognize host selling or cannot be unduly influenced by it. As such, a complete ban would be overly restrictive and thus unfair to advertisers.

Third, the FCC could change its definition of a child to someone under 14 years old, mirroring the current television ratings system. It is unlikely that the FCC would lower the child-adult age threshold. It has consistently protected children from advertising that "takes advantage of the trust that children place in program characters," ${ }^{30}$ and there is no evidence that 14 to 16 year olds are immune to host selling and the like.

Fourth, the television industry could add a TV-17 ratings category for adult-oriented programs and an "A" designation-for adult advertising - to its current "S," "L," "V," and "D" designations. This ratings adjustment would parallel an earlier one by the Motion Picture Association of America, which split its original PG rating into PG (to denote movies with adult dialogue) and PG-13 (to denote movies with intense violence, dialogue, and language). The gap between a TV-14 rating and a TV-MA rating is problematic for parents and regulators; a new TV-17 rating is congruent with the FCC's definition of a child and would denote adult programming without the " $\mathrm{R}$ " or " $\mathrm{X}$ " rating stigma implied by a TV-MA rating. $\mathrm{A}$ new "A" designation would merely indicate that adult advertising techniques, such as host selling, may be in use. Armed with these new designations and a v-chip modified to recognize them, parents could more effectively block their children from viewing inappropriate television programs. This solution would ensure that producers of adult-oriented television programs, like the WWF, can host sell without breaching the Children's Television Act of 1990. Given that the current television ratings system is voluntary, this solution would require no new legislation. It would, however, entail additional costs, including the creation and installation of new v-chips that recognize the suggested rating scheme. Such costs may be prohibitive. 
Finally, the easiest solution to introduce and thus most likely to be embraced by all involved is the introduction of a new category of paid programming called the program-length commercial. Programs such as the WWF would be preceded by a disclaimer that the following is a program-length commercial (similar to that used by paid programming infomercials). An on-screen identifier such as PLC (program-length commercial) would run during the entire program. This identifier would appear in the corner of the television screen in a fashion similar to the network identifiers that often now appear. A ban on such types of programming aimed at children (e.g., Saturday morning television and family hour) would continue, with an amendment to the Children's Television Act of 1990, allowing the use of this type of advertising for programs rated TV-14 or above, provided the disclaimer and identifier air throughout the program.

\section{CONCLUSION}

In response to criticisms about the gratuitous sex and violence that children see when watching professional wrestling on television, Vince McMahon retorted that it was not his job to prevent children from viewing such programs. Instead, parents should be responsible for monitoring their children's television viewing. For McMahon, "RAW IS WAR is TV-14, [so] if parents are concerned about content, they should insist their kids watch the [toned down] Saturday morning [program], which is more youth friendly." ${ }^{31}$

Programming like that produced by the WWF can still expose older children to both host selling and program-length commercials. This is particularly true now that HEAT has moved to MTV, with a primary target market consisting of what the FCC would define as children (under age 17). The problem is posed by an inconsistency in the definition of a child assumed by the television ratings system and the FCC. Specifically, the television industry defines a child as someone under 14 years old, but the FCC defines a child as someone under 17 years old. As a result, producers of adult-oriented programs cannot simultaneously host sell to adults and adhere to the Children's Television Act of 1990 without incurring the television equivalent of an " $\mathrm{X}$ " rating. 
To rectify the problem in the long term, the television industry, with the cooperation of v-chip manufacturers, could add a TV-17 ratings category for adult-oriented programs and an "A" designation —for adult advertising— to its current "S," "L," "V," and "D" designations. In the short term, or as a permanent additional aid to parents, the industry could add a new category of paid programming called program-length commercial, coupled with a new on-screen identifier. Thus, both immediate and longer-term solutions are possible.

\section{Future Research}

Host selling to children is illegal. Is host selling to adults ethical? Researchers may find that many adults are insensitive to subtle types of host selling, such as tightly interwoven programs and advertising. If so, then it could be argued that such host selling should be banned.

Another researchable question is the consistency of host selling policies in other countries. WWF programming is beamed to 120 countries and is translated into 11 languages, ${ }^{32}$ which means that professional wrestling is an international industry. An analysis of public broadcasting policy in English-speaking countries such as Canada, the United Kingdom, and Australia, where unmodified versions of U.S. programs are aired, may reveal similar problems.

Host selling is seemingly used during other, non-sports-entertainment programs. For example, U.S. game shows such as Family Feud host sell to adults. At least once per show, Louis Anderson, the current comedian-host, turns to the camera, holds up an electronic home version of the game, and informs viewers that they can buy it from Tiger Electronics. He tells them to look for his picture on the package to ensure that they buy the "real official Family Feud Home Version." This clear case of host selling to adults during a program rated TV-PG has the unintended consequence of host selling to older children. Thus, researchers and public policy makers could also study other sources of inadvertent host selling to children. 


\section{NOTES}

1. Lawrie Mifflin, TV Rating System May Actually Lure Youths to Violent Shows, Study Finds, New York Times (27 March 1997), A22.

2. Jack W. Brehm, Responses to Loss of Freedom: A Theory of Psychological Reactance (Morristown, NJ: General Learning Press, 1972).

3. Joanne Cantor and Amy Nathanson, Predictors of Children's Interest in Violent Television Programs, Journal of Broadcasting \& Electronic Media 41 (spring 1997): 155-67.

4. John Horn, Hollywood Lands in the Hot Seat, Newsweek (25 September 2000), 68.

5. FCC http://www.fcc.gov/vchip/. 2000.

6. FCC http://www.fcc.gov/Bureaus/Cable/News_Releases/1998/ nrcb8003.html. 1998c.

7. Kevin J. Shanahan and Charles M. Hermans, Addressing Oversights in the Regulation of Children's Television, Academy of Marketing Science Conference Proceedings, Montreal, PQ, 2000, 259-63.

8. FCC http://www.fcc.gov/Bureaus/Mass_Media/Notices/1997/ da970391.txt. 1997a.

9. James Hall, Mighty Minutes: An Illustrated History of Television's Best Commercials (New York: Harmony Books, 1984).

10. FCC http://www.fcc.gov/Bureaus/Mass_Media/Notices/1998/ da982 149.txt. 1998a.

11. Alison Alexander, Louise M. Benjamin, Keisha Hoerrner, and Darrell Roe, We'll Be Back in a Moment: A Content Analysis of Advertisements in Children's Television in the 1950's, Journal of Advertising 3 (fall 1998): 1-9.

12. Ibid.

13. Ibid.

14. FCC, 1998a.

15. FCC http://www.fcc.gov/Bureaus/Mass_Media/Notices/1997/ da970324.txt. 1997b.

16. Alexander et al., We'll Be Back in a Moment.

17. Israel D. Nebenzahl and Eugene Secunda, Consumers' Attitudes Toward Product Placement in Movies, International Journal of Advertising 12 (1993): 1-11.

18. John Leland, Why America's Hooked on Wrestling, Newsweek (7 February 2000), 46-55.

19. Lynn Rosellini, Lords of the Ring, US News and World Report 126 (17 May 1999), 53-58. 
20. Joy Fine, Wrestling Has Choke-Hold on Cable Fans, Advertising Age 71 (10 April 2000):20-22.

21. Kelly Shermach, Wrestling on a Peak: Keeps One Eye on Valley, Marketing News 31 (12 May 1997):24-25.

22. Ibid.

23. Leland, Why America's Hooked on Wrestling.

24. Now It Can Be Told: Those Pro Wrestlers Are Just Having Fun, New York Times (10 February 1989), A1.

25. Rosellini, Lords of the Ring.

26. Fine, Wrestling Has Choke-Hold.

27. FCC http://www.fcc.gov/Bureaus/Mass_Media/Public_Notices/ da980950.txt. 1998d.

28. FCC, 1997a.

29. http://www.parentstv.org/about/faq/faq.asp

30. FCC, 1998a.

31. Rosellini, Lords of the Ring.

32. Leland, Why America's Hooked on Wrestling. 